\title{
Wet Etching of Ion-implanted GaN Crystals by AZ-400K Photoresist
}

\section{C.A. Carosella, B. Molnar, S. Schiestel ${ }^{1}$ and J.A. Sprague}

Naval Research Laboratory, Washington DC 20375

${ }^{1}$ George Washington University, Washington, DC

\section{ABSTRACT}

The photoresist developer AZ-400K, commonly used to remove AIN encapsulant layers on $\mathrm{GaN}$ crystalline films, is found to also etch certain as-grown $\mathrm{GaN}$ films. Even as-grown GaN films, which can not be etched in AZ-400K, however can be etched if amorphized by ion implantation. Etch rates of as high as $450 \AA / \mathrm{min}$. were observed. The etching proceeds linearly in $\mathrm{GaN}$ in the first few minutes to a depth corresponding to the depth of the amorphous region. Subsequently, the etching rate saturates. Annealing of the highly amorphized samples up to $1000^{\circ} \mathrm{C}$ for one minute in a $\mathrm{N}_{2} / \mathrm{H}_{2}$ gas mixture does not reduce the etch rate, but for lower doses we observed a reduction of the etch rate. Observations of etching depth under various ion-implanted conditions could be correlated with the number of displacements per atoms (dpa) required for amorphization.

\section{INTRODUCTION}

The semiconductor $\mathrm{GaN}$ is currently the subject of interest for technological innovations in optoelectronics and in high-power, high-temperature device operations $[1,2]$. Ion implantation is an accepted method for integration of such devices into circuits. Doping of GaN by ion implantation requires an encapsulant layer such as AlN for minimization of the GaN decomposition during high temperature activation annealing [3]. The use of an encapsulant layer demands a method for the selective removal of this layer after the annealing treatment. The photoresist developer, AZ-400K is reported to be such a selective wet etching agent for AlN over GaN [4]. Wet etching of GaN has been studied in basic and acid solutions [5,6,7]. Recent studies indicated that AZ-400K does not etch $\mathrm{GaN}$ at solution temperatures up to $80^{\circ} \mathrm{C}[8,9]$. This paper demonstrates that $\mathrm{GaN}$ can be etched in AZ-400K after ion implantation.

\section{EXPERIMENTAL}

The wurzite GaN single crystal films used in this study were grown either by chemical vapor deposition (CVD) or molecular beam epitaxy (MBE) on c-plane (0001) oriented sapphire substrates. They were grown at eight different laboratories. The layer thicknesses were between 1 and $15 \mu \mathrm{m}$. The layers were highly resistive semi-insulating (SI) or conductive n- or p-type.

The etching experiments were conducted by immersing GaN samples, partly covered with apiezon wax in the photoresist developer AZ-400K at room temperature and $80^{\circ} \mathrm{C}$. The etching depth and surface roughness were measured with a KLA Tencor P-10 surface profilometer. The GaN samples were implanted either with $\mathrm{B}^{+}$and $\mathrm{Ar}^{+}$ions in order to study the ion dose, energy and mass dependence of the damage. The ion 
energies were varied between 30 and $180 \mathrm{keV}$, the ion doses from $1^{*} 10^{14}$ to $5^{*} 10^{16}$ ions $/ \mathrm{cm}^{2}$. One part of the sample was masked during implantation.

Some samples were annealed after ion implantation in a conventional tube furnace up to $1000^{\circ} \mathrm{C}$ in a $\mathrm{N}_{2} / 10 \% \mathrm{H}_{2}$ gas mixture in order to study the damage recovery influence on the etching. The surface morphology of selected samples was investigated by SEM.

\section{RESULTS}

A variety of GaN films were used to study the influence of growth method, thickness, carrier concentration and mobility on etching properties. In the first step, the as-grown $\mathrm{GaN}$ films were immersed in $\mathrm{AZ}-400 \mathrm{~K}$ at room temperature and at $80^{\circ} \mathrm{C}$. Some of the GaN films could be etched as grown without any further treatment. Table 1 summarizes the etching results for the different, as grown GaN films. None of the MOCVD GaN films could be etched, whereas 3 out of $4 \mathrm{MBE}$ grown GaN films we studied showed an etching in AZ-400K. We could not observe any influence of film thickness, carrier concentration or mobility on the etching behavior. However, damaging by ion implantation promoted etching.

Some of the MOCVD GaN films were implanted with B and Ar ions of different energies and at various ion doses. The first implantation experiments were performed with $\mathrm{Ar}$ ions with a constant ion energy of $100 \mathrm{keV}$ and the ion dose was varied between $10^{15}$ and $5 * 10^{16}$ ions $/ \mathrm{cm}^{2}$. The results are presented in fig. 1 . The implanted $\mathrm{GaN}$ layers turned brown with increasing ion dose and for the highest ion dose of $5^{*} 10^{16}$ ions $/ \mathrm{cm}^{2}$ a dark brown, metallic shiny layer was obtained. Four-point probe resistivity measurements on a semi-insulating GaN film implanted with $5 * 10^{16} \mathrm{Ar}$ ions $/ \mathrm{cm}^{2}$ showed a conductance of about $100(\Omega \mathrm{cm})^{-1}$.

Table 1: Different types of GaN samples used for etching experiments in AZ-400K, and their etching behavior.

\begin{tabular}{|l|l|l|l|l|l|}
\hline Growth type & $\begin{array}{l}\text { Carrier } \\
\text { concentration } \\
{\left[1 / \mathrm{cm}^{3}\right] * 10^{17}}\end{array}$ & $\begin{array}{l}\text { Thickness } \\
{[\mu \mathrm{m}]}\end{array}$ & $\begin{array}{l}\text { Mobility } \\
{\left[\mathrm{cm}^{2} / \mathrm{Vs}\right]}\end{array}$ & $\begin{array}{l}1 \text { hour } \\
25^{\circ} \mathrm{C}\end{array}$ & $\begin{array}{l}1 \text { hour } \\
80^{\circ} \mathrm{C}\end{array}$ \\
\hline MOCVD & 1.5 & 2 & -15 & NO & NO \\
\hline MOCVD & 2.5 & 1.6 & +9 & NO & NO \\
\hline HVPE & 0.7 & 16 & -630 & NO & NO \\
\hline MOCVD & 3 & 3.1 & -300 & NO & NO \\
\hline MOCVD & S.I. & 3 & & NO & NO \\
\hline MBE & 20 & 2 & -230 & YES & YES \\
\hline MBE & 0.1 & 2.8 & & YES & YES \\
\hline MBE & 1 & 1 & & NO & NO \\
\hline MBE & 10 & .3 & +5 & YES & YES \\
\hline
\end{tabular}

F99W11.70 


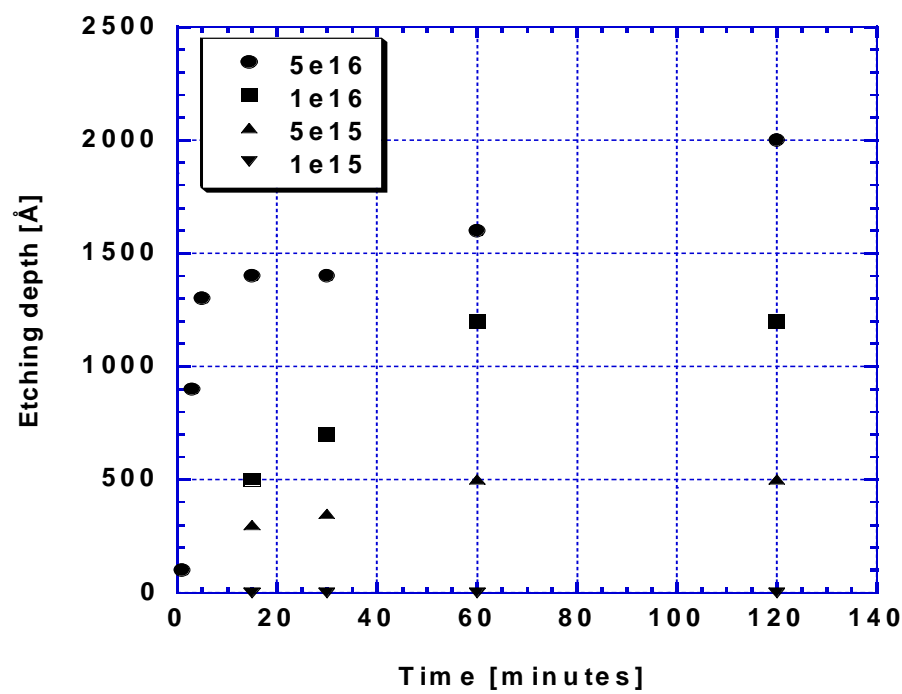

Fig.1: Dependence of etching depth on etching time for the implantation of $100 \mathrm{keV} \mathrm{Ar}$ ions at different ion doses.

After ion implantation, the GaN films were immersed in AZ-400K $80^{\circ} \mathrm{C}$. Fig. 1 shows the etching depth for different $\mathrm{Ar}$ ion doses and etching times. We observe a linear etching during the first five minutes for the highest ion dose $\left(5 * 10^{16}\right.$ ions $/ \mathrm{cm}^{2}$, circles). The surface roughness of the etched area is comparable to the one of the untreated surface and amounts to $\pm 100 \AA$. After 5 minutes the etching profile seems to saturate at about $1400 \AA$, which roughly corresponds to the damage region induced by ion implantation, which was calculated/estimated by TRIM [10]. After 60 minutes pores start to develop at the etched surface, up to $1500 \AA$ in depth. Simultaneously with the development of pores at the etched surface, the etching depth increases slightly more. The etching behavior for the highest implantation dose of $\left(5^{*} 10^{16}\right.$ ions $\left./ \mathrm{cm}^{2}\right)$ differs from the ones implanted at lower doses. For all samples implanted with an ion dose of $\leq 10^{16}$ ions $/ \mathrm{cm}^{2}$, the etching of the implanted area was accompanied immediately by the presence of deep pores $(500-1500 \AA)$. The etching depth (saturation) decreased with decreasing ion dose and was $1200 \AA$ for $10^{16}$ ions $/ \mathrm{cm}^{2}$ and $500 \AA$ for $5 * 10^{15}$ ions $/ \mathrm{cm}^{2}$. No etching, except for pore formation, occurred for an ion dose of $10^{15}$ ions $/ \mathrm{cm}^{2}$. Pores with a depth up to $1000 \AA$ were present after 1 hour; they increased to $1500 \AA$ after another hour in $\mathrm{AZ}-400 \mathrm{~K}$ at $80^{\circ} \mathrm{C}$.

Tan et al. reported an amorphization of GaN for the implantation of $90 \mathrm{keV} \mathrm{Si}$ ions at ion doses $>10^{16}$ ions $/ \mathrm{cm}^{2}$ at liquid nitrogen temperature [11]. At room temperature, the amorphization dose is higher. For example, Liu, et al. report that $3 * 10^{14}$ $\mathrm{Ca}^{+}$ions $/ \mathrm{cm}^{2}$ at $180 \mathrm{keV}$ are necessary to initiate amorphization of $\mathrm{GaN}$ at $77^{\circ} \mathrm{K}$, but 
$8 * 10^{14}$ ions $/ \mathrm{cm}^{2}$ are needed at room temperature[12]. Liu, et al. report that $\mathrm{GaN}$ is amorphized at $77^{\circ} \mathrm{K}$ with $180 \mathrm{keV}$ Ar ions at about 5-6 dpa [13]. We calculate the number of dpa for the ion energies and ion doses of our experiments using TRIM. The results of these calculations for $100 \mathrm{keV}$ Ar ions and ion doses from $10^{15}$ to $5 * 10^{16}$ ions $/ \mathrm{cm}^{2}$ are shown in fig. 2. For the lowest ion dose, the number of dpa is less than one Therefore, it is not surprising that for this ion dose no etching of the implanted GaN was observed. For the higher ion doses, the depth of the damage region roughly corresponds to the saturation level of the etching depth.

TRIM calculations for the implantation of $1 * 10^{16} \mathrm{~B}^{+}$ions $/ \mathrm{cm}^{2}$ with ion energies of 30 and $100 \mathrm{keV}$ revealed a number of dpa at the damage peak of less than 3, too small to amorphize $\mathrm{GaN}$. Experimental results for $\mathrm{GaN}$ implanted with $\mathrm{B}$ ions at these doses and energies revealed no etching.

In another set of experiments we examined the annealing influence at $900^{\circ} \mathrm{C}$ and $1000^{\circ} \mathrm{C}$ in $\mathrm{N}_{2} / \mathrm{H}_{2}$ gas on implanted GaN films ( $100 \mathrm{keV}$ Ar ions, $10^{15}-5^{*} 10^{16}$ ions $\left./ \mathrm{cm}^{2}\right)$. The etch rate for the sample implanted at $5^{*} 10^{16}$ ions $/ \mathrm{cm}^{2}$ before and after annealing is the same, and almost all of the etching is completed in the first five minutes. In contrast, the annealing slows the etch rates for the lower implantation doses $\left(<10^{16}\right.$ ions $/ \mathrm{cm}^{2}$ ) and no saturation was observed. There is also a delayed onset of etching in these samples. At $10^{16}$ ions $/ \mathrm{cm}^{2}$, etching commences at 30 minutes; at $5 * 10^{15}$ ions $/ \mathrm{cm}^{2}$, etching begins after $1 \mathrm{hr}$ in $\mathrm{AZ}-400 \mathrm{~K}$ at $80^{\circ} \mathrm{C}$.

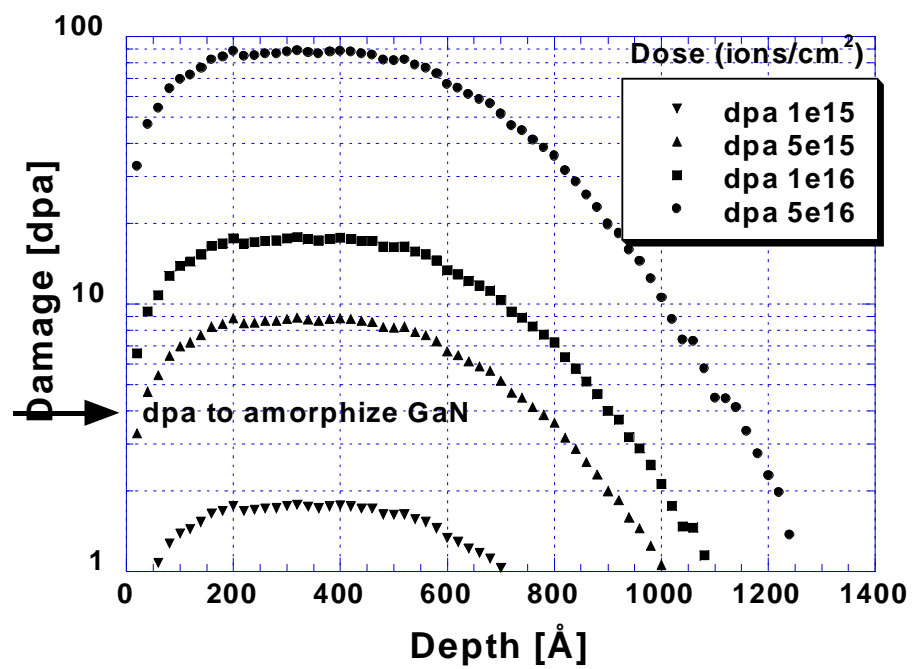

Fig.2: Damage calculations for the implantation of $100 \mathrm{keV}$ Ar ions at different ion doses. The dpa to amorphize GaN is the approximate threshold from references [11] and [13]. 
Again, we observed no etching at all for the lowest implantation dose of $10^{15}$ ions $/ \mathrm{cm}^{2}$. From these data, we conclude that some of the damage is recoverable at the lower doses, but no recovery is possible at the highest dose.

Ion energy should also limit the etching depth. To investigate this effect, $\mathrm{Ar}$ ions of 30 or $180 \mathrm{keV}$ were implanted. The predicted damage range for $30 \mathrm{keV}$ is $400 \AA$ and for $180 \mathrm{keV}, 2000 \AA$. The ion doses were chosen to result in a comparable dpa. They were $1.6 * 10^{16}$ ions $/ \mathrm{cm}^{2}$ for $30 \mathrm{keV}$, and $5.5 * 10^{16}$ ions $/ \mathrm{cm}^{2}$ for $180 \mathrm{keV}$. In fig. 3, the results of these etching experiments are presented. The saturation etching depth for 30 $\mathrm{keV}$ is $600 \AA$, and for $180 \mathrm{keV} 2000 \AA$. For $30 \mathrm{keV}$, etching of the implanted layer was observed after 2 minutes and it was completely removed after 5 minutes. At $180 \mathrm{keV}$ the implanted layer started to etch after 5 minutes and was completely removed after 10 minutes.

To demonstrate the potential of etching of ion implanted GaN for applications, a GaN film was implanted through a mask. The mask was a TEM grid with a grid size of $20 \mu \mathrm{m}$. Ar ions with an energy of $100 \mathrm{keV}$ and an ion dose of $5^{*} 10^{16}$ ions $/ \mathrm{cm}^{2}$ were implanted through the mesh. The sample was then immersed for 5 minutes in AZ-400K at $80^{\circ} \mathrm{C}$. Fig. 4 shows a SEM image and a profilometer scan taken after etching.

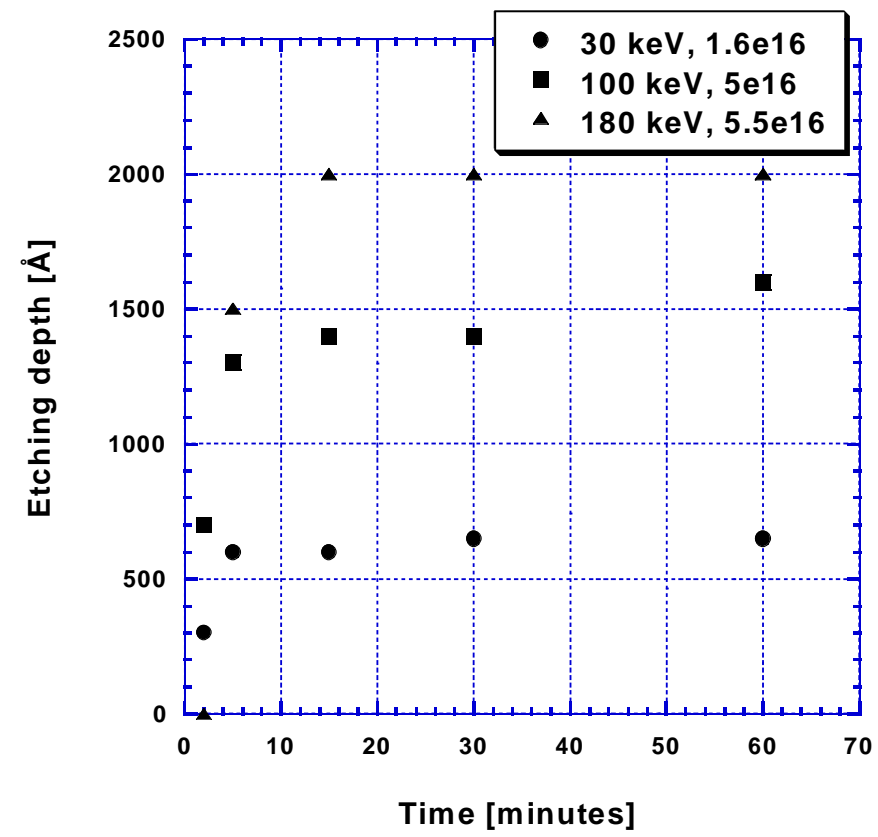

Fig.3: Dependence of etching depth on etching time for different Ar ion energies. 

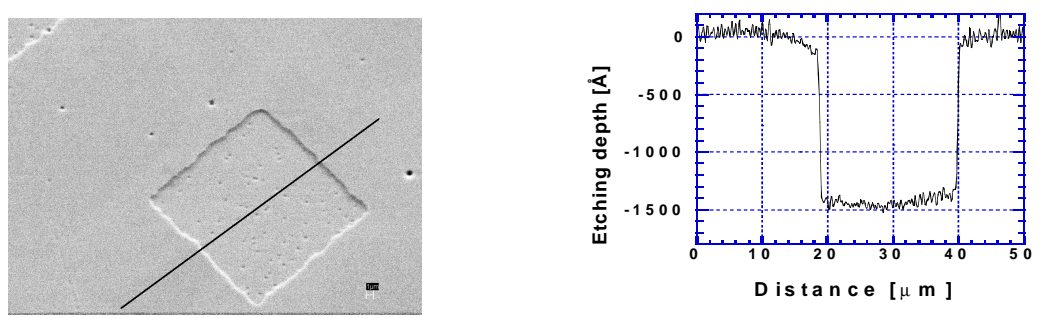

Fig.4: SEM and profilometer scan of ion implanted and etched GaN

\section{CONCLUSIONS}

We have demonstrated the wet etching of ion-implanted GaN in AZ-400K at $80^{\circ} \mathrm{C}$. The etching process takes place in two steps: first, there is a rapid, linear rate of removal of material. Secondly, saturation of the etching depth is observed. The thickness of the material that easily etches away increases with ion energy and ion dose, and decreases with the ion mass. The behavior is predictable from TRIM calculations and experimental measurement of the dpa needed to amorphize GaN. We observe that the roughness of the etched surface was at least as good as the original surface. Finally, implantation through masks offers a potential of three-dimensional patterning of GaN.

\section{REFERENCES}

[1] S.S. Nakamura, M. Senoh, S. Nagahama, N. Iwassa, T. Yamada, T. Matsushita, H. Kikoyu and Y. Sugimoto, Jpn. J. Appl. Phys. 35, L74 (1996)

[2] S. Binari, L.B. Rowland, W. Kruppa, G. Kelner, K. Doverspike and D.K. Gaskill, Electron. Lett. 30, 1248 (1994)

[3] J.C. Zolper, J. Han, R.M. Biefeld, S.B. Van Deusen, W.R. Wampler, D.J. Reiger, S.J. Pearton, J.S. Williams, H.H. Tan, R.F. Karlicek,Jr. and R.A. Stall, J. Electron. Mater. 27, 179 (1998)

[4] J.R. Mileham, J.S. Pearton, C.R. Abernathy, J.D. MacKenzie, R.J. Shul and S.P. Kilcoyne, Appl. Phys. Lett., 67, 1119 (1995)

[5] T.I. Chu, J. Electrochem. Soc. 118, 1200 (1971)

[6] M. Seeelmann-Eggebert, J.L. Weyher, H. Obloh, H. Zimmermann, A. Rar and S. Porowski, Appl. Phys. Lett. 71, 2635 (1997)

[7] D.A. Stocker, E.F. Schubert and J.M. Redwing, Appl. Phys. Lett. 73 (1998)

[8] J.R. Mileham, S.J. Pearton, C.R. Abernathy, J.D. MacKenzie, R.J. Shul and S.P. Kilcoyne, J.Vac. Sci. Technol. A 14, 836 (1996)

[9] C. Vartuli, S.J. Pearton, C.R. Abernathy, J.D. MacKenzie, . Ren, J.C. Zolper and

R.J. Shul, Solid-State Electronics 41, 1947 (1997)

[10] J.F. Ziegler and J.P. Biersak, SRIM-2000.38, IBM Corp. (1999)

[11] H.H. Tan, J.S. Williams, J. Zou, D.H. Cockayne, S.J. Pearton and R.A. Stall, Appl. Phys. Lett. 69 (16), 2364 (1996)

[12] C. Liu, A. Wenzel, K. Volz, B. Rauschenbach, Nucl. Instr. Meth. B 148, 396 (1999)

[13] C. Liu, B. Mensching, M. Zeitler, K. Volz and B. Rauschenbach, Phys. Rev. B, Vol. 57, No. 4, 2530 (1998) 